\title{
The spatial scale of competition from recruits on an older cohort in Atlantic salmon
}

\author{
Sigurd Einum • Keith H. Nislow $\cdot$ Simon McKelvey • \\ John D. Armstrong
}

Received: 22 March 2011/Accepted: 8 June 2011/Published online: 28 June 2011

(C) The Author(s) 2011. This article is published with open access at Springerlink.com

\begin{abstract}
Competitive effects of younger cohorts on older ones are frequently assumed to be negligible in species where older, larger individuals dominate in pairwise behavioural interactions. Here, we provide field estimates of such competition by recruits on an older age class in Atlantic salmon (Salmo salar), a species where observational studies have documented strong body size advantages which should favour older individuals in direct interactions. By creating realistic levels of spatial variation in the density of underyearling (YOY) recruits over a $1-\mathrm{km}$ stretch of a stream, and obtaining accurate measurements
\end{abstract}

Communicated by Marc Mangel.

S. Einum $(\bowtie)$

Department of Biology, Centre for Conservation Biology,

Norwegian University of Science and Technology,

7491 Trondheim, Norway

e-mail: sigurd.einum@bio.ntnu.no

S. Einum

Norwegian Institute for Nature Research,

Tungasletta 2, 7485 Trondheim, Norway

K. H. Nislow

USDA Forest Service Northern Research Station,

201 Holdsworth NRC, 160 Holdsworth Way,

Amherst, MA 01003, USA

e-mail: knislow@fs.fed.us

S. McKelvey

Conon District Salmon Fisheries Board, c/o C.K.D. Galbraith,

17 Old Edinburgh Road, Inverness IV2 3HF, UK

e-mail: CONONDSFB@aol.com

\section{J. D. Armstrong}

Marine Scotland Science Freshwater Laboratory,

Faskally, Pitlochry, Perthshire PH16 5LB, UK

e-mail: J.Armstrong@MARLAB.AC.UK of individual growth rates of overyearlings (parr) from capture-mark-recapture data on a fine spatial scale, we demonstrate that high YOY density can substantially decrease parr growth. Models integrating multiple spatial scales indicated that parr were influenced by YOY density within $16 \mathrm{~m}$. The preferred model suggested parr daily mass increase to be reduced by $39 \%$ when increasing YOY density from 0.0 to $1.0 \mathrm{~m}^{-2}$, which is well within the range of naturally occurring densities. Reduced juvenile growth rates will in general be expected to reduce juvenile survival (via increased length of exposure to freshwater mortality) and increase generation times (via increased age at seaward migrations). Thus, increased recruitment can significantly affect the performance of older cohorts, with important implications for population dynamics. Our results highlight that, even for the wide range of organisms that rely on defendable resources, the direction of competition among age classes cannot be assumed a priori or be inferred from behavioural observations alone.

Keywords Age structure - Density dependence . Exploitative $\cdot$ Interactive $\cdot$ Inter-cohort competition

\section{Introduction}

Competition from recruits has the potential to reduce performance of older individuals in terms of fitness-related traits. The strength of such competition will be a function of the degree of overlap in resource requirements among the cohorts, and the nature of competitive interactions. For organisms that rely on resources that can be defended, body size is commonly a strong predictor of competitive dominance. This in turn may cause a competitive situation where the older cohort (because older individuals are 
larger) has an advantage over the younger one (Schwinning and Weiner 1998; Schmitt and Holbrook 1999). In contrast, if resources are not defendable and depleted through exploitation, competition may favour individuals in younger cohorts because each of them has a lower resource requirement (Schwinning and Weiner 1998; Aljetlawi and Leonardsson 2002; de Roos et al. 2002; Byström and Andersson 2005). Furthermore, even for the wide range of organisms where being large provides benefits during competition for favourable foraging positions, smaller individuals occupying neighbouring areas may intercept mobile resources that otherwise would have entered the territories of older ones, exerting shadow competition (Elliott 2002). It seems particularly likely that such effects may be pronounced in organisms with large fecundity, where recruits may greatly outnumber older age classes. Thus, a priori predictions regarding the direction of inter-cohort competition may not be based solely on size-dependent direct aggressive interactions among individuals.

Due to indeterminate growth of individual fish, their populations constitute particularly striking examples of age-structure resulting in strong size-structure. It therefore seems clear that understanding inter-cohort competition to a large extent depends on knowledge about how body size differences influence competitive effects. However, for those species where a large body is believed to provide an advantage in social interactions, there appears to be a bias in experimental studies of inter-cohort competition, with a particular focus on effects of older age classes on younger ones (e.g. Jones 1987; Webster and Hixon 2000; Nordwall et al. 2001; Webster 2004; Kaspersson and Höjesjö 2009; Samhouri et al. 2009). Furthermore, researchers may implicitly have assumed that inter-cohort competition is unidirectional, with an effect of larger cohorts on smaller ones. For example, time series analyses of cod (Gadus morhua L.) population dynamics have assumed that 1 year olds may influence underyearlings, but not vice versa (Stenseth et al. 1999; Bjørnstad et al. 1999). Yet, for such organisms with high fecundity, cohort strength may show dramatic declines with age, causing older cohorts to be vastly outnumbered and negatively influenced by recruits even in the presence of large body size differences (Kaspersson et al. 2010).

These issues are highly relevant for stream-living salmonid fishes, which also represent a particularly tractable study system for field manipulation studies. In many of these species, juveniles originating from several potentially competing cohorts live in sympatry. These fish usually defend a single spatial location against intruders at any given time, although individuals may move among different patches of space through time (Steingrimsson and Grant 2008). Behavioural observations suggest strong body size effects on the ability of salmon parr to control access to space (Cutts et al. 1999). Experimental field studies have confirmed that the presence of older age classes negatively influences the growth performance of younger ones (Nordwall et al. 2001; Kaspersson and Höjesjö 2009). Yet, as outlined above, social interactions and size-based dominance do not necessarily imply a lack of competitive effects of younger cohorts on older ones, and a recent correlative study suggests negative effects of underyearling density on yearling energetics in brown trout (Salmo trutta; Kvingedal and Einum 2011). In the absence of information of such effects, population models have either ignored inter-cohort competition (using single-cohort stockrecruitment models; Elliott 1993), or assumed specific inter-cohort competition scenarios (Paul et al. 2000; Einum et al. 2008a).

In this study, we take advantage of our ability to create realistic spatial variation in Atlantic salmon (Salmo salar) recruitment in a natural stream to test for effects on growth rates (an important determinant of individual fitness and life-history expression) of tagged individuals from an older cohort. Our overall goal was to provide one of the first field estimates of the strength of such an inter-cohort effect on organisms whose populations are strongly regulated by social interactions.

\section{Materials and methods}

\section{Study site}

The study was conducted in Glen Meinich, a small tributary to the River Conon, Ross-shire, northern Scotland, which is located above migration barriers and hence is without natural salmon spawning. Brown trout (Salmo trutta L.) were present at low density. In addition, salmon parr ( $\geq 1+$ age) resulting from routine stocking for management purposes in previous years were present. The procedure used for this routine stocking (introduction of batches of eyed eggs ca. every $20 \mathrm{~m}$ along the stream) ensured a relatively homogenous spatial distribution of parr. Such stocking was not conducted in the year of the present study. The mean \pm SD water temperature (logged every 15 min with a Solinst levelogger) during the study duration (25 May-28 June) was $14.5 \pm 3.6^{\circ} \mathrm{C}$.

Juvenile stocking

A sample of 10 female and 10 male Atlantic salmon caught in a fish trap in the River Blackwater, a tributary to the River Conon, during October 2008, were used to produce ten full-sibling family groups which were incubated separately in a hatchery at Contin. On 1 May 2009, the resulting 
young-of-the-year (YOY) reached the first-feeding stage, and they were transferred to a common tank and fed ad lib using commercial fish food. On 11 May, six groups each comprising 1,500 YOY were transported to Glen Meinich. Each group was placed within the stream in a basket, with a distance of ca. $250 \mathrm{~m}$ between each basket. The fish were then left overnight for recovery before the baskets were turned over, allowing them to swim out. This was done 2 weeks prior to the capturing and tagging of parr to allow for the YOY to re-distribute, and hence reduce changes in YOY spatial distributions during the period over which parr growth was measured. Mean \pm SD body length and mass at release was $29.1 \pm 1.2 \mathrm{~mm}$ and $0.12 \pm 0.03 \mathrm{~g}$, respectively $(n=34)$.

\section{Tagging of salmon parr}

During 25-28 May, salmon parr were captured and tagged. The stream was electrofished [bank-based generator (Honda EU10i), control box (Electracatch WF6), fixed cathode and portable anode] by a single pass in a reach stretching from $85 \mathrm{~m}$ upstream of the lowermost YOY release site to $75 \mathrm{~m}$ downstream of the uppermost one. The stream was fished in 2-m longitudinal increments, and each fish caught was held in a bucket associated with its capture location before processing. Only salmon parr were targeted during this sampling, and other observed fish (including released YOY) were thus ignored to minimize disturbance and subsequent movement among them. Captured parr were anaesthetized (MS222, $80 \mathrm{ppm}$ ), and the longitudinal location of capture $( \pm 2 \mathrm{~m})$, body length (total, $\pm 1 \mathrm{~mm}$ ) and mass $( \pm 0.01 \mathrm{~g})$ of each individual was recorded before a passive integrated transponder (PIT) tag was inserted into the body cavity. All parr were released after recovery back into the stream at the location of capture.

Recapture of tagged salmon parr and quantification of YOY spatial distributions

During 25-28 June, the stream was electrofished again with a single pass over the same reach of the stream that had been sampled previously. In addition, to enable recapture of tagged fish that had moved short distances out of this area, 50-m stretches below and above the previously fished area were included. Salmon and trout of all ages were caught, and the location of capture $( \pm 2 \mathrm{~m})$, body length $( \pm 1 \mathrm{~mm})$ and mass $( \pm 0.01 \mathrm{~g})$ of each individual fish was recorded. For 2-m sections with high numbers $(>10)$ of YOY, a sub-sample of ten individuals was measured. PITtagged fish were identified and killed before being stored in alcohol, whereas all other fish were placed in recovery baskets before being re-released into the stream. The
PIT-tagged fish were later aged by scale reading (all individuals were confirmed to be 1 year old).

\section{Habitat measurements}

On 28 June 2009, we measured wetted stream width and abundance of shelters available for fish every $4 \mathrm{~m}$ (i.e. at the centre of every second 2-m section) along the 1,100-mlong study reach of the stream. Shelter abundance (number of interstitial spaces $>5 \mathrm{~cm}$ deep) was measured using a 13- $\mathrm{mm}$ tube on a randomly chosen $0.25-\mathrm{m}^{2}$ square for each width transect according to the method described in Finstad et al. (2007). In addition, the dominant mesohabitat class (fast flowing riffle, slower flowing shallow glide, and deeper slow flowing pool) was determined for each $2-\mathrm{m}$ section. Based on these measurements, the mean $\pm \mathrm{SD}$ stream width and shelter abundance was $4.7 \pm 1.3 \mathrm{~m}$ and $1.9 \pm 1.6$ shelters, respectively. The mesohabitat was dominated by riffles (73\% of transects), followed by pools $(15 \%)$ and glides (12\%). The mean \pm SD stream temperature during the study period (measured every $15 \mathrm{~min}$ using a Solinst Levelogger) was $14.5 \pm 3.7^{\circ} \mathrm{C}$.

\section{Statistical analyses}

To describe the overall spatial distribution of salmon YOY relative to the position of stocking locations, we modelled the total number caught per section as a function of mesohabitat class, shelter abundance, and distances to closest YOY stocking location in the upstream direction using Generalized Additive Models (the gam function) with a Poisson error distribution within the $m g c v$ package (Wood 2004). Colinearity among these variables was not a problem (all VIFs $<1.4$; Zuur et al. 2009). Stream width (wetted widths at the measuring transect closest to each section, i.e. at a maximum distance of $2 \mathrm{~m}$ from a section) was used as an offset variable to control for variation in area among sections. Because all 2-m sections had YOY stocked both in the upstream and downstream directions, and the release points were regularly spaced along the stream, the distance to the closest stocking location in upstream direction implicitly gives information about the equivalent distance in downstream direction. The smoothed distance term therefore incorporates the effect of both downstream and upstream dispersal. Residuals from this model showed a spatial trend for a decrease in numbers when going upstream, and we therefore included a linear term for location (in $\mathrm{km}$ ) within the stream. Comparisons of different fixed effects structures was done using a backwards selection procedure where different fixed effects were removed sequentially until no further model improvement in terms of AIC (based on ML) could be attained (Zuur et al. 2009). 
Due to the predominantly drift feeding behaviour of juvenile Atlantic salmon, we modelled effects of fish density in a unidirectional manner, such that the growth (i.e. final body mass when controlling for effect of initial body mass) of a focal parr was potentially influenced by the density indices of fish in its own 2-m section as well as those located upstream of it. In a previous study, we identified the spatial scale over which YOY influence the growth of each other in such a directional way to be approximately $10 \mathrm{~m}$ (Einum et al. 2011). We therefore started our modelling by assuming a priori that the growth of parr in a given section could be influenced by the mean density index of YOY and parr over five sections ("own" section plus the four closest upstream ones). Density indices per section were calculated as the numbers captured divided by the area of the section. We then modelled individual parr final body mass $\left(Y_{j}\right)$ as a function of (1) numbers of days from tagging to recapture (range 2934 days, with $99 \%$ of individuals being recaptured within 30-32 days), (2) initial body mass (including a squared term to include potential nonlinearity), (3) YOY density index, (4) density index of older salmon, (5) density index of older trout (only two YOY trout were found, effects of these were therefore not tested for), (6) shelter abundance, and (7) mesohabitat type. Colinearity among these variables (excluding the categorical mesohabitat variable) was insubstantial (all VIFs <1.35). We first fitted a generalised least squares model with the $g l s$ function within the nlme package (Pinheiro et al. 2009):

$Y_{j}=\alpha+\beta_{i} X_{i, j}+\varepsilon_{j}$

where $i$ is a variable index and $j$ an individual index, and where $\varepsilon_{j} \sim N\left(0, \sigma^{2}\right)$. As an alternative model, we used a linear mixed model which contained a random effect of section $\left(b_{k}\right.$; i.e. testing for correlation among individuals within sections):

$Y_{j, k}=\alpha+\beta_{i} X_{i, j}+b_{k}+\varepsilon_{j}$

In the comparison between these two alternative models, model 2 was slightly better than model 1 (likelihood ratio test, $P=0.050)$. Residuals from this model showed no spatial patterns, but some heteroscedasticity relative to initial mass. We therefore modelled residual variance as a power function of initial mass using the varPower function within the nlme package to stabilise residuals (Zuur et al. 2009). This improved the AIC $(\triangle \mathrm{AIC}=7.3)$. We proceeded with this model to compare different fixed effects structures. This was done using a backwards selection procedure where different fixed effects were removed sequentially until no further model simplification could be made without causing a significant $(P<0.05)$ decrease in log-likelihoods (calculated based on ML; Zuur et al. 2009).
When the final model had been identified, we continued by fitting this model for fish densities calculated over different longitudinal spatial scales, ranging from 2 (only density within own section) to $40 \mathrm{~m} \mathrm{(19} \mathrm{sections} \mathrm{in}$ upstream direction). This was the maximal spatial scale that could be used (the uppermost pit-tagged fish was recaptured at $1,010 \mathrm{~m}$, and densities were quantified up to $1,050 \mathrm{~m})$. AIC was used to identify the spatial scale that gave the best model fit.

All statistical analyses were conducted using the statistical software $\mathrm{R}$ v.2.9.2. (R Development Core Team 2009).

\section{Results}

Body sizes and movement

A total of 679 salmon parr (mean \pm SD wet body mass and total length: $3.96 \pm 0.83 \mathrm{~g}, 72 \pm 5 \mathrm{~mm}$ ) were caught and tagged during the first sampling. During the second sampling, 290 of these fish were recaptured. In addition, during the second sampling, a total of 2,853 YOY salmon (40 $\pm 0.3 \mathrm{~mm})$, and 2 YOY (44 mm) and 104 overyearling trout $(104 \pm 33 \mathrm{~mm})$ were caught. There was no significant difference in initial body size between individuals that were recaptured and those that were not (ANOVA, body mass: $F_{1,677}=1.56, P=0.21$; body length: $F_{1,677}=0.92$, $P=0.34)$.

For the tagged parr that were recaptured, their individual mean \pm SD increase in body mass and length was $27.0 \pm 13.5$ and $8.4 \pm 2.9 \%$, respectively (initial size: $3.99 \pm 0.83 \mathrm{~g}, \quad 72 \pm 5 \mathrm{~mm}$; final size: $5.05 \pm 1.07 \mathrm{~g}$, $78 \pm 5 \mathrm{~mm})$. Their mean $\pm \mathrm{SD}$ relative distance of movement between the two samplings was $12 \pm 96 \mathrm{~m}$ in the upstream direction (Fig. 1). The corresponding absolute distance was $26 \pm 26 \mathrm{~m}$. However, these values were largely driven by a few individuals moving over larger distances, and the majority of the fish (84\%) were recaptured within $10 \mathrm{~m}$ from the location of first capture.

\section{YOY spatial distribution}

Observed mean \pm SD YOY density in the 2-m sections was $0.60 \pm 0.59 \mathrm{~m}^{-2}$, and the range $\left(0-5.6 \mathrm{~m}^{-2}\right)$ was within the range that can be observed in natural populations when measured over such small spatial scales (Teichert et al. 2011). The spatial distribution of YOY salmon was best described by a model containing mesohabitat, distance to stocking location, and absolute location within the stream. This model was slightly better than the full model which also included shelter abundance $(\triangle \mathrm{AIC}=0.9)$ as well as any of the models with one fewer terms (all 


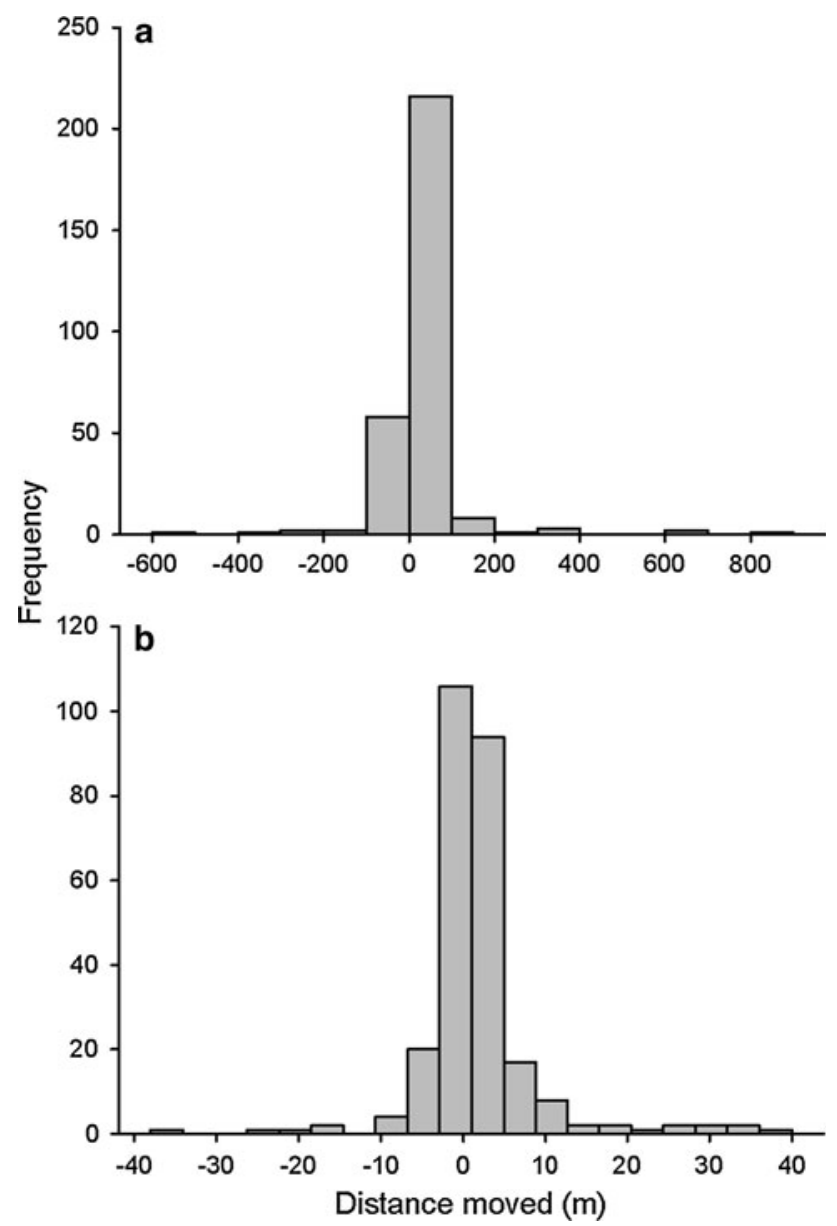

Fig. 1 Distance moved by Atlantic salmon (Salmo salar) parr (overyearlings) from tagging to recapture in Glen Meinich. All data are shown in (a), whereas only individuals that moved less than $40 \mathrm{~m}$ are shown in (b) to provide a higher spatial resolution

$\Delta$ AIC $>262)$. YOY abundance decreased when going upstream (Table 1). In addition, it was higher in riffles and lower in pools than in glides (Table 1). The spatial smoother shows how YOY abundance is highest in the vicinity and downstream of stocking locations (Fig. 2). It decreases and reaches a minimum at about $170 \mathrm{~m}$, before increasing again as sections approach downstream stocking locations (stocking occurred ca. every $250 \mathrm{~m}$ ). Thus, the patchy YOY stocking was successful in creating a spatial pattern in YOY abundance, and the observed distributions suggest that the majority of YOY movements occurred in a downstream direction.

\section{Salmon parr growth}

For the complete dataset and when using the a priori spatial scale $(10 \mathrm{~m})$, the model selection procedure produced a final model which included initial body mass and YOY density as fixed variables, whereas all other variables were excluded (Model 1 in Table 2). AIC values for this model
Table 1 Parametric terms in the generalized additive model that best describe the spatial variation in YOY Atlantic salmon (Salmo salar) abundance (number of YOY per sampled section) in Glen Meinich

\begin{tabular}{lcll}
\hline & Parameter & SE & $P$ \\
\hline Intercept & -2.145 & 0.067 & $<0.001$ \\
Pool habitat & -0.577 & 0.107 & $<0.001$ \\
Riffle habitat & 0.694 & 0.072 & $<0.001$ \\
Absolute location $(\mathrm{km})$ & -1.293 & 0.068 & $<0.001$
\end{tabular}

For the estimated smoothed effect of distance to closest stocking site, see Fig. 2

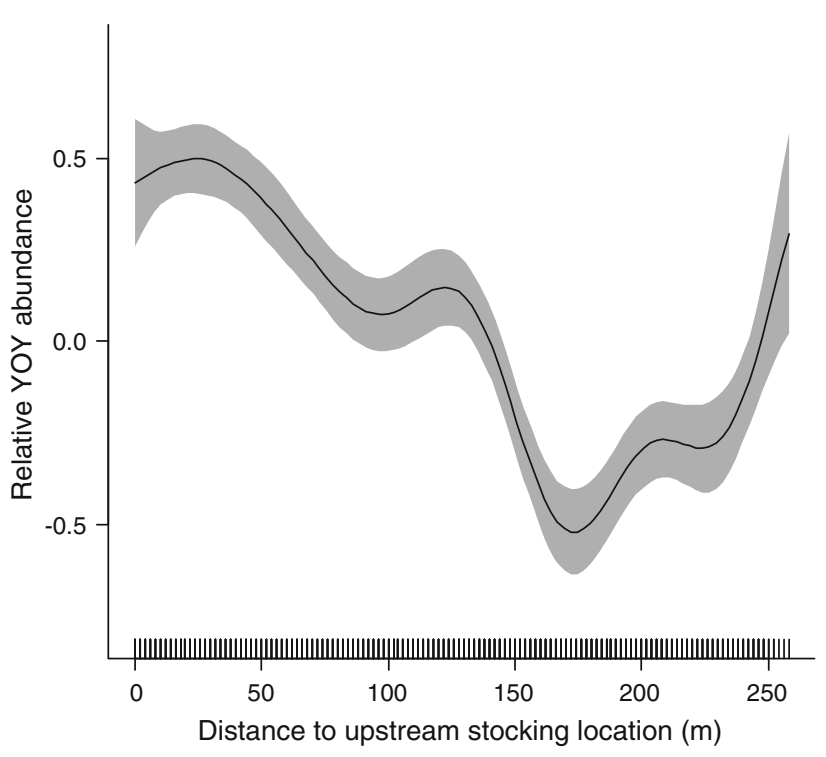

Fig. 2 Estimated smoothing curve (shaded area represents 95\% confidence interval) for the best generalized additive model describing the spatial variation in YOY Atlantic salmon abundance in Glen Meinich as a function of distance to the nearest upstream stocking location while controlling for parametric terms (see Table 1). Etchings on the inside of the $x$-axis indicate locations of data points. Effective degrees of freedom for the smoother are 7.73, and the significance is $P<0.001$

decreased considerably when increasing the spatial scale up to $16 \mathrm{~m}$, after which the values increased again (Fig. 3). These results indicated that increasing the spatial scale to $16 \mathrm{~m}$ resulted in a better explanatory model of parr growth (i.e. final body size when controlling for initial body size), but that going beyond this distance did not improve it. When repeating the model selection procedure using this best spatial scale, the same variables remained in the model following model selection, and the effect of YOY density became more pronounced (Model 2 in Table 2). Using the observed mean final parr body mass $(5.05 \mathrm{~g})$ as a reference, the slope of the YOY effect in Model 2 (Table 2) suggests an $8.4 \%$ reduction in final mass $(4.63 \mathrm{~g})$ when increasing YOY density from 0.0 to $1.0 \mathrm{~m}^{-2}$. To visualise the effect of YOY density on final body weight while controlling for 
Table 2 Summaries of two linear mixed effects models describing the spatial distribution of Atlantic salmon parr wet body mass $(\mathrm{mg})$ in Glen Meinich at recapture as a function of initial body mass and fish density

\begin{tabular}{llrl}
\hline & Parameter $\pm \mathrm{SE}$ & \multicolumn{1}{l}{$t$} & $P$ \\
\hline Model 1 & & & \\
Random & $0.15(0.49)$ & & \\
Intercept & $861.94 \pm 173.77$ & 4.96 & $<0.001$ \\
Initial mass (mg) & $1.09 \pm 0.04$ & 26.74 & $<0.001$ \\
YOY density (fish m & \\
Model 2 & $-322.99 \pm 85.23$ & -3.79 & $<0.001$ \\
Random & & & \\
Intercept & $0.13(0.44)$ & & \\
Initial mass (mg) & $947.55 \pm 175.06$ & 5.41 & $<0.001$ \\
YOY density (fish m & \\
& $1.09 \pm 0.04$ & 26.72 & $<0.001$ \\
\hline
\end{tabular}

Model 1 is the final model after stepwise selection when fish densities were calculated over a spatial scale of $10 \mathrm{~m}$ (the a priori chosen spatial scale), whereas Model 2 is the equivalent when using a spatial scale of $16 \mathrm{~m}$ (the best spatial scale). Estimated parameters for Random are the SD of random intercepts in the models, with SD of residual variation given in parentheses. $n$ for both models is 290 individuals, originating from 201 different recapture sections

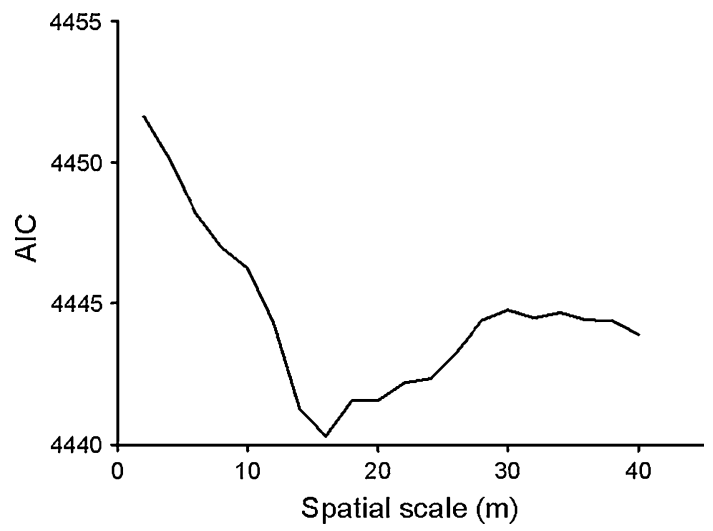

Fig. 3 AIC values of the linear mixed model describing variation in Atlantic salmon final body mass in Glen Meinich as a function of YOY densities when these were calculated over different spatial scales

initial body weight, we used residuals from the linear regression between these two variables (Fig. 4).

\section{Discussion}

By creating spatial variation in the local density of underyearling (YOY) Atlantic salmon and obtaining accurate measurements of individual growth rates of overyearlings (parr) from capture-mark-recapture data in the field, we demonstrated that high YOY density decreased parr growth rates (final body mass when controlling for initial body mass). Thus, in spite of a well-known advantage exhibited

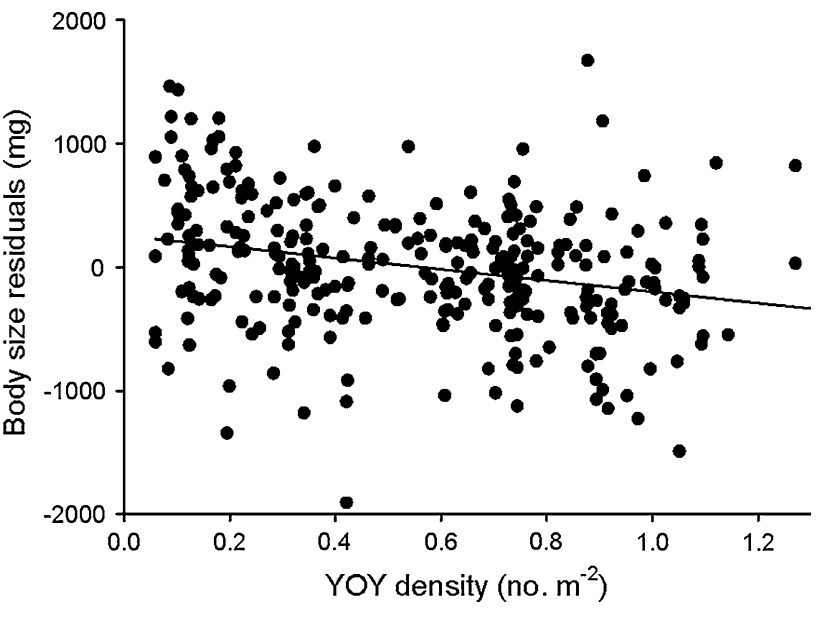

Fig. 4 Relationship between Atlantic salmon parr body growth (measured as residuals from relationship between initial and final mass) and YOY density (measured over $16 \mathrm{~m}$ ) in Glen Meinich. Regression line is added for illustrative purpose

by older, larger fish in pairwise competitive interactions, increased recruitment can significantly affect the performance of older cohorts, with important implications for population dynamics. This highlights the fact that even for organisms that are considered to rely on resources that are defendable (in the present example space), the direction of competitive asymmetries among age classes cannot be assumed a priori or be inferred from behavioural observations alone. Our approach both provides robust estimates which can help to improve our population models and understanding of population dynamics, and point to potential mechanisms underlying these actions.

A key component of the study was our ability to create spatial variation in densities of YOY fish in a way that is relevant to real-world conditions. Point-stocking of YOY salmon along a natural river caused a spatial pattern in their distributions as mapped ca. 1.5 months later. The smoothed relationship estimated from the GAM suggested a relatively high and decreasing abundance down to ca. $125 \mathrm{~m}$ below stocking locations, indicating limited and predominantly downstream movements. In addition, a weak increase when approaching the downstream stocking location (close to $250 \mathrm{~m}$ ) suggests an even more limited upstream movement. These results are in accordance with previous studies of YOY salmon movements away from nests (Crisp 1995; García de Leániz et al. 2000; Webb et al. 2001; Einum et al. 2008b; Foldvik et al. 2010), and confirm that the spatial distribution of nests gave predictable patterns in the distribution of YOY. Given that the spatial distribution of spawning sites of Atlantic salmon rivers is inherently patchy (Moir et al. 1998). and that year-to-year variability in recruitment can be high (Jensen and Johnsen 1999; Bagliniere et al. 2005). the levels of variation in local YOY abundance that we achieved in our experiment are 
likely to be highly relevant to wild populations. Although allowing for natural re-distribution of YOY entails a reduced control over local population densities compared to when using a more traditional experimental design using stream enclosures, the degree of realism is increased by allowing for dispersal processes, and hence avoiding the risk of applying treatments that would not be reflected in natural populations.

A second substantial advantage of the current design, which involved continuous spatial gradients in density and collection of data on a fine spatial scale, is that it allows for inference of the relevant spatial scale over which competitive effects occur, and can estimate competition parameters on that scale. Our models indicated that YOY density within $16 \mathrm{~m}$ had the strongest influence on overyearling growth. These local effects are consistent with previous research on the importance of local density on growth in salmonids (Einum et al. 2006). Uncertainties in these estimates arise due to parr movements combined with the use of data based on recapture locations in the model. However, most overyearlings were sedentary over the course of the study ( $84 \%$ had moved less than $10 \mathrm{~m}$ ). The estimated spatial scales are therefore unlikely to be strongly biased. Furthermore, the spatial scales estimated here are similar to those obtained for effects of YOY densities on their own growth across a range of streams in the River Conon catchment (Einum et al. 2011).

Our study was not designed to identify the specific mechanisms responsible for the negative effects of underyearling density on overyearlings. However, the local scale of these effects points to some likely possibilities. Depletion of prey in the drift (i.e. shadow competition; Elliott (2002) is one potential mechanism, with the spatial scale of effects we observed being consistent with the expected scale of shadow competition given that most drift appears to derive locally (within $10 \mathrm{~m}$; McLay 1970). Another potential mechanism is increased metabolic or time costs associated with aggression directed towards YOY. A recent study by Kaspersson et al. (2010) gives some insights into these processes. They reared parr brown trout (Salmo trutta) individually in tanks together with YOY. The parr size advantage (similar in magnitude to that in the present study) enabled them to occupy and defend a central position within the tank, whereas YOY primarily used marginal downstream areas. Yet, with increasing density of YOY, the parr spent an increasing amount of time showing aggressive behaviour. Whereas the number of feeding attempts by parr was independent of YOY density, their feeding efficiency (number of successful foraging attempts) decreased, and they adopted a darker body coloration indicative of increased stress. The increased aggression and reduced feeding efficiency suggests that growth effects may be expected even in the absence of effects on food abundance.
The magnitude of the growth effect of YOY on parr was strong. Using the mean start weight among the parr that were recaptured $(3.96 \mathrm{~g})$, the estimated $8.4 \%$ reduction in final mass when increasing YOY density from 0.0 to $1.0 \mathrm{~m}^{-2}$, which is a range of densities commonly observed within natural populations (e.g. Imre et al. 2005; Teichert et al. 2011), represents a $39 \%$ difference in daily mass increase $\left(0.89\right.$ vs. $0.55 \%$ day $\left.^{-1}\right)$. The period examined in our study constitutes one of relatively high food abundance and growth rate compared to later in the summer (Poff and Huryn 1998; Letcher and Gries 2003; Bacon et al. 2005; Orpwood et al. 2006), and is therefore particularly important for the parr in their preparation for overwintering and migration to the sea (see below). Our parameter estimates may be biased if a pronounced change in the YOY distribution occurred during the experimental period, since our data on this distribution was from the end of the period. To minimize the disturbance to this distribution during the first capture of parr, a single pass of electrofishing during which YOY were not removed from their locations was conducted. Thus, we do not have information on the temporal consistency of the YOY spatial distribution throughout the experimental period. However, a previous study of Atlantic salmon showed that dispersal of emergers from nests over a similar spatial scale as those considered here occurred during a short period $(80 \%$ of recorded dispersers during 14-18 days; García de Leániz et al. 2000). Our YOY were fed in the hatchery for 11 days and then allowed to redistribute for 2 weeks in the stream after being released, and hence presumably achieved a relatively stable spatial distribution prior to the start of the parr growth measurements. It therefore seems unlikely that such a bias, if present, would be pronounced. Parameter estimates may also depend on the environmental conditions in which the competition takes place. The temperatures experienced during the study were quite typical of temperate salmonid streams, and were within the range providing close to maximum growth for Atlantic salmon (Forseth et al. 2001). Thus, we have no reason to believe that these results would differ much under other temperature regimes. Habitat characteristics were also typical of smaller spawning tributaries, being dominated by riffles and considerable amounts of shelter, within which both YOY (particularly along the stream margins where currents are lower; Nislow et al. 1999) and parr would find suitable feeding locations (Finstad et al. 2011). Thus, we consider these results to have a high degree of generality for Atlantic salmon populations.

The observed consequences of competition with a younger cohort can be manifest in population dynamics. Atlantic salmon parr migrate to sea (smolt) in spring at age 1-8 after reaching a size threshold (Økland et al. 1993), with variation in smolt age existing both among and within 
populations due to differences in growth rates. Reduced growth rates will therefore increase the age at smolting and/or reduce the smolt body size. Increased smolt age will cause freshwater mortality to act over a longer period and hence may reduce the production of smolt as well as returning adults (mortality at sea is density-independent; Jonsson et al. 1998), whereas reduced smolt size may result in reduced sea survival (Kallio-Nyberg et al. 2007; Salminen et al. 1995). If the observed effects on growth rates translate into such effects on survival, this may lead to the paradoxical situation that a long-term increase in recruitment (e.g. due to supplementary hatchery releases or increased dispersion of suitable breeding habitat) can have a negative effect on adult abundance (Einum et al. 2008a). Finally, competitive effects by recruits on older cohorts which translate into survival effects may contribute to increase the temporal variability in salmon population abundance (Persson et al. 1998; Aikio and Pakkasmaa 2003).

Our results demonstrate that inter-cohort competition in Atlantic salmon is not limited to older cohorts influencing younger ones, which has been the traditional focus for empirical studies both for salmonid fish and other organisms where body size provides a competitive advantage (e.g. Schmitt and Holbrook 1999; Nordwall et al. 2001; Webster 2004; Eitam et al. 2005; Kaspersson and Höjesjö 2009; Samhouri et al. 2009). Negative effects of recruit density on parr growth occurred despite pronounced difference in mean body size (mean body length of YOY was $51 \%$ of that of parr) and previous studies showing strong benefits of body size in competitive interactions (Cutts et al. 1999). Thus, negative effects of recruits on older cohorts may not be limited to organisms that are primarily exploitative competitors, such as detritus-feeding crustaceans (Aljetlawi and Leonardsson 2002) or planktivorous fish (Byström and Andersson 2005), but may also apply to the wide range of organisms that rely on resources that appear to be defendable (e.g. competition for space), and where body size advantages can be assumed to be strong. For predictive, mechanistic population models, these results suggest that scenarios allowing for such effects should be examined. For age-specific time-series analyses, the potential for time-lags in both directions may be evaluated, with negative effects of younger cohorts on survival of older ones suggesting that mechanisms such as those observed here translate into effects on population dynamics.

Acknowledgments We thank the landowner for permission to undertake this work, and Lynn Brydon, Tim Burton, Jason Henry, Per Harald Olsen, Pål Anders Martinussen, Zlatko Petrin, Dave Stewart and Mick Wyndham for technical assistance. Financial support was provided by the Research Council of Norway. This study was conducted in accordance with national animal care guidelines.
Open Access This article is distributed under the terms of the Creative Commons Attribution Noncommercial License which permits any noncommercial use, distribution, and reproduction in any medium, provided the original author(s) and source are credited.

\section{References}

Aikio S, Pakkasmaa S (2003) Relatedness and competitive asymmetry-implications for growth and population dynamics. Oikos 100:283-290

Aljetlawi AA, Leonardsson K (2002) Size-dependent competitive ability in a deposit-feeding amphipod, Monoporeia affinis. Oikos 97:31-44

Bacon PJ, Gurney WSC, Jones W, Mclaren IS, Youngson AF (2005) Seasonal growth patterns of wild juvenile fish: partitioning variation among explanatory variables, based on individual growth trajectories of Atlantic salmon (Salmo salar) parr. J Anim Ecol 74:1-11

Bagliniere JL, Marchand F, Vauclin V (2005) Interannual changes in recruitment of the Atlantic salmon (Salmo salar) population in the River Oir (Lower Normandy, France): relationships with spawners and in-stream habitat. ICES J Mar Sci 62:695-707

Bjørnstad ON, Fromentin JM, Stenseth NC, Gjøsaeter J (1999) Cycles and trends in cod populations. Proc Natl Acad Sci USA 96:5066-5071

Byström P, Andersson J (2005) Size-dependent foraging capacities and intercohort competition in an ontogenetic omnivore (Arctic char). Oikos 110:523-536

Crisp DT (1995) Dispersal and growth rate of 0-group salmon (Salmo salar $\mathrm{L}$.) from point-stocking to together with some information from scatter-stocking. Ecol Freshw Fish 4:1-8

Cutts CJ, Metcalfe NB, Taylor AC (1999) Competitive asymmetries in territorial juvenile Atlantic salmon, Salmo salar. Oikos 86:479-486

de Roos AM, Leonardsson K, Persson L, Mittelbach GG (2002) Ontogenetic niche shifts and flexible behavior in size-structured populations. Ecol Monogr 72:271-292

Einum S, Sundt-Hansen L, Nislow KH (2006) The partitioning of density-dependent dispersal, growth and survival throughout ontogeny in a highly fecund organism. Oikos 113:489-496

Einum S, Nislow KH, Reynolds JD, Sutherland WJ (2008a) Predicting population responses to restoration of breeding habitat in Atlantic salmon. J Appl Ecol 45:930-938

Einum S, Nislow KH, McKelvey S, Armstrong JD (2008b) Nest distribution shaping within-stream variation in Atlantic salmon juvenile abundance and competition over small spatial scales. J Anim Ecol 77:167-172

Einum S, Robertsen G, Nislow KH, McKelvey S, Armstrong JD (2011) The spatial scale of density-dependent growth and implications for dispersal from nests in juvenile Atlantic salmon. Oecologia 165:959-969

Eitam A, Blaustein L, Mangel M (2005) Density and intercohort priority effects on larval Salamandra salamandra in temporary pools. Oecologia 146:36-42

Elliott JM (1993) A 25-year study of production of juvenile sea-trout, Salmo trutta, in an English Lake District stream. Can Spec Publ Fish Aquat Sci 118:109-122

Elliott JM (2002) Shadow competition in wild juvenile sea-trout. J Fish Biol 61:1268-1281

Finstad AG, Einum S, Forseth T, Ugedal O (2007) Shelter availability affects behaviour, size-dependent and mean growth of juvenile Atlantic salmon. Freshw Biol 52:1710-1718

Finstad AG, Armstrong JD, Nislow KH (2011) Freshwater habitat requirements of Atlantic salmon. In: Aas $\varnothing$, Einum S, Klemetsen 
A, Skurdal J (eds) Atlantic salmon ecology. Wiley, Oxford, pp 67-88

Foldvik A, Finstad AG, Einum S (2010) Relating juvenile spatial distribution to breeding patterns in anadromous salmonid populations. J Anim Ecol 79:501-509

Forseth T, Hurley MA, Jensen AJ, Elliott JM (2001) Functional models for growth and food consumption of Atlantic salmon parr, Salmo salar, from a Norwegian river. Freshw Biol 46:173-186

García de Leániz C, Fraser N, Huntingford FA (2000) Variability in performance in wild Atlantic salmon, Salmo salar L., fry from a single redd. Fish Manag Ecol 7:489-502

Imre I, Grant JWA, Cunjak RA (2005) Density-dependent growth of young-of-the-year Atlantic salmon Salmo salar in Catamaran Brook, New Brunswick. J Anim Ecol 74:508-516

Jensen AJ, Johnsen BO (1999) The functional relationship between peak spring floods and survival and growth of juvenile Atlantic salmon (Salmo salar) and brown trout (Salmo trutta). Funct Ecol 13:778-785

Jones GP (1987) Competitive interactions among adults and juveniles in a coral-reef fish. Ecology 68:1534-1547

Jonsson N, Jonsson B, Hansen LP (1998) The relative role of densitydependent and density-independent survival in the life cycle of Atlantic salmon Salmo salar. J Anim Ecol 67:751-762

Kallio-Nyberg I, Saloniemi I, Koljonen ML (2007) Effects of parental and smolt traits on the marine survival of released Atlantic salmon (Salmo salar). Aquaculture 272:254-266

Kaspersson R, Höjesjö J (2009) Density-dependent growth rate in an age-structured population: a field study on stream-dwelling brown trout Salmo trutta. J Fish Biol 74:2196-2215

Kaspersson R, Höjesjö J, Pedersen S (2010) Effects of density on foraging success and agression in age-structured groups of brown trout. Anim Behav 79:709-715

Kvingedal E, Einum S (2011) Intra- and intercohort spatial density dependence in juvenile brown trout (Salmo trutta). Can J Fish Aquat Sci 68:115-121

Letcher BH, Gries G (2003) Effects of life history variation on size and growth in stream-dwelling Atlantic salmon. J Fish Biol 62:97-114

McLay C (1970) A theory concerning distance travelled by animals entering drift of a stream. J Fish Res Bd Can 27:359-370

Moir HJ, Soulsby C, Youngson AF (1998) Hydraulic and sedimentary characteristics of habitat utilized by Atlantic salmon for spawning in the Girnock Burn, Scotland. Fish Manag Ecol 5:241-254

Nislow KH, Folt CL, Parrish DL (1999) Favorable foraging locations for age-0 Atlantic salmon: application to the restoration of populations and habitats. Ecol Appl 9:1085-1099

Nordwall F, Naslund I, Degerman E (2001) Intercohort competition effects on survival, movement, and growth of brown trout (Salmo trutta) in Swedish streams. Can J Fish Aquat Sci 58:2298-2308

Økland F, Jonsson B, Jensen AJ, Hansen LP (1993) Is there a threshold size regulating seaward migration of brown trout and Atlantic salmon? J Fish Biol 42:541-550

Orpwood JE, Griffiths SW, Armstrong JD (2006) Effects of food availability on temporal activity patterns and growth of Atlantic salmon. J Anim Ecol 75:677-685
Paul AJ, Post JR, Sterling GL, Hunt C (2000) Density-dependent intercohort interactions and recruitment dynamics: models and a bull trout (Salvelinus confluentus) time series. Can J Fish Aquat Sci 57:1220-1231

Persson L, Leonardsson K, de Roos AM, Gyllenberg M, Christensen B (1998) Ontogenetic scaling of foraging rates and the dynamics of a size-structured consumer-resource model. Theor Popul Biol 54:270-293

Pinheiro J, Bates D, DebRoy S, Sarkar D, the R Core team (2009) nlme: linear and nonlinear mixed effects models. $\mathrm{R}$ package version 3.1-93

Poff N, Huryn A (1998) Multi-scale determinants of secondary production in Atlantic salmon (Salmo salar) streams. Can J Fish Aquat Sci 55:201-217

R Development Core Team (2009) R: a language and environment for statistical computing. R Foundation for Statistical Computing. ISBN 3-900051-07-0. http://www.R-project.org

Salminen M, Kuikka S, Erkamo E (1995) Annual variability in survival of sea-ranched Baltic salmon, Salmo salar L.: significance of smolt size and marine conditions. Fish Manag Ecol 2:171-184

Samhouri JF, Steele MA, Forrester GE (2009) Inter-cohort competition drives density dependence and selective mortality in a marine fish. Ecology 90:1009-1020

Schmitt RJ, Holbrook SJ (1999) Mortality of juvenile damselfish: Implications for assessing processes that determine abundance. Ecology 80:35-50

Schwinning S, Weiner J (1998) Mechanisms determining the degree of size asymmetry in competition among plants. Oecologia 113:447-455

Steingrimsson SO, Grant JWA (2008) Multiple central-place territories in wild young-of-the-year Atlantic salmon Salmo salar. J Anim Ecol 77:448-457

Stenseth NC, Bjørnstad ON, Falck W, Fromentin JM, Gjøsaeter J, Gray JS (1999) Dynamics of coastal cod populations: intra- and intercohort density dependence and stochastic processes. Proc $\mathrm{R}$ Soc Lond B 266:1645-1654

Teichert MAK, Foldvik A, Forseth T, Ugedal O, Einum S, Finstad AG, Hedger RD, Bellier E (2011) Effects of spawning distribution on juvenile Atlantic salmon (Salmo salar) density and growth. Can J Fish Aquat Sci 68:43-50

Webb JH, Fryer RJ, Taggart JB, Thompson CE, Youngson AF (2001) Dispersion of Atlantic salmon (Salmo salar) fry from competing families as revealed by DNA profiling. Can J Fish Aquat Sci 58:2386-2395

Webster MS (2004) Density dependence via intercohort competition in a coral-reef fish. Ecology 85:986-994

Webster MS, Hixon MA (2000) Mechanisms and individual consequences of intraspecific competition in a coral-reef fish. Mar Ecol Progr Ser 196:187-194

Wood SN (2004) Stable and efficient multiple smoothing parameter estimation for generalized additive models. J Am Stat Assoc 99:673-686

Zuur AF, Ieno EN, Walker NJ, Saveliev AA, Smith GM (2009) Mixed effects models and extensions in ecology with $\mathrm{R}$. Springer, New york 